\title{
OPERATIONS THROUGHPUT AS A DETERMINANT OF GOLDEN-HOUR IN MASS-GATHERING MEDICINE
}

\author{
I. D. Khan', B. Asima'2, S. A. Khan² \\ ARMY COLLEGE OF MEDICAL SCIENCES AND BASE HOSPITAL, NEW DELHI, INDIA ${ }^{1}$ \\ RESIDENT NUCLEAR MEDICINE, ARMY HOSPITAL RESEARCH AND REFERRAL, NEW DELHI, INDIA²
}

\begin{abstract}
Background. Golden-hour, a time-tested concept for trauma-care, involves a systems approach encompassing healthcare, logistics, geographical, environmental and temporal variables. Golden-hour paradigm in massgathering-medicine such as the Hajj-pilgrimage entwines along healthcare availability, accessibility, efficiency and interoperability; expanding from the patient-centric to public-health centric approach. The realm of massgathering-medicine invokes an opportunity for incorporating operations-throughput as a determinant of goldenhour for overall capacity-building and interoperability.

Methods. Golden-hour was evaluated during the Indian-Medical-Mission operations for Hajj-2016; which established, operated and coordinated a strategic network of round-the-clock medical operations. Throughput was evaluated as deliverables/time, against established Standard-Operating-Procedures for various clinical, investigation, drug-dispensing and patient-transfer algorithms. Patient encounter-time, waiting-time, turnaroundtime were assessed throughout echeloned healthcare under a patient-centric healthcare-delivery model. Dynamic evaluation was carried out to cater for variation and heterogeneity.

Results. Massive surge of 394013 patients comprising 225103 males (57.1\%) and 168910 females (42.9\%) overwhelmed the throughput capacities of outpatient attendance, pharmacy, laboratory, imaging, ambulance, referrals and documentation. There was a delay in attendance, suspicion, diagnosis and isolation of patients with communicable infections. The situational-analysis of operations-throughput highlights wasted turnaround-time due to mobilization of medical-team, diverting critical healthcare resources away from emergency situations.

Conclusions. Time being a crucial factor in the complexity of medical-care, operations-throughput remains an important determinant towards interoperability of bottlenecks, thereby being a determinant of golden-hour in mass-gathering-medicine. Early transportation of a patient to definitive-care reduces treatment initiation-time, notwithstanding logistics of communication, evacuation, terrain and weather being deterministic in outcome. Golden-hour needs to be emphasized under a population-based approach targeting the clientele towards administering first-aid and reaching out to hospital within the golden-hour.
\end{abstract}

KEY WORDS: golden-hour; operations throughput; mass-gathering medicine; turnaround-time; definitive-care; population-based approach.

\section{Introduction}

Golden-hour, a hitherto time-tested concept for trauma-care, has been found useful across the entire ambit of emergency health-systems. Golden-hour involves a systems approach encompassing healthcare, logistics, geographical, environmental and temporal variables.

Mass-Gathering-Medicine applies to situations where a mass-gathering overwhelms accessibility, interoperability and public-safety response to medical-emergencies. Mass-Gathering-Medicine involves higher rates of morbidity and mortality attributable to infections,

Corresponding author: Inam Danish Khan

Clinical Microbiology and Infectious Diseases, Army College of Medical Sciences and Base Hospital, New Delhi 110010, India Phone number: +91 9836569777

E-mail: titan_afmc@yahoo.com trauma, environment, occupation, lifestyle, substance-abuse and disasters [1, 2]. Hajj pilgrimage is a 5-day outdoor unbounded peaceful mass-gathering involving a moving assemblage of over 3.5 million pilgrims from 200 countries, engaged in prayers, supplications and strenuous rituals in densities of 9 people/ $\mathrm{m}^{2}$ or more, in harsh desert climate of SaudiArabia. Mass-Gathering-Medicine at Hajj is challenged by issues of healthcare availability, accessibility, infection control, rapid-diagnosis, on-site treatment, referral, evacuation, and response to disasters and public-health emergencies $[3,4]$.

The realm of Mass-Gathering-Medicine invokes an opportunity for incorporating operations-throughput as a determinant of golden- 
hour for overall capacity-building and interoperability. This prospective study explored the perspective of golden-hour across the spectrum of Mass-Gathering-Medicine.

\section{Methods}

The perspective of golden-hour as a determinant of operations-throughput was evaluated during the Indian Medical Mission operations for Hajj-2016, which established, operated and coordinated a strategic network of roundthe-clock medical operations in Mecca, Medina and Jeddah during Hajj-2016 pilgrimage from 01 Aug to 30 Oct 2016. The mission framework comprised of (a) Mobile medical task-forces detailed for strategic mass-gathering locations such as mosques, religious places, bus-stops, train-stations and along the pilgrimage assemblage during the five critical days of Hajj, to cater for 5000-100000 pilgrims per congregation. (b) 18 Static-clinics having basic first-aid capabilities catered for 6000-9000 pilgrims/ clinic residing in over 400 buildings in Mecca and Medina (c) One mobile referral tent-clinic with 35 tent-clinics having medical attendance facilities only, catered for 3000-4000 pilgrims in over 5000 tents in Mina and Arafat, as well as $1,40,000$ unsheltered pilgrims in Muzdalifah. (d) Two strategically sited 40-bedded secondarycare referral facilities for critical-care, internalmedicine, general and orthopaedic surgery, gynaecology, paediatrics, psychiatry, dermatology, isolation, lab-medicine and radiology (e) Tertiary-care patient transfers coordinated with 28 Saudi Arabian hospitals.

Golden-hour as a determinant of operations throughput was evaluated across the spectrum of Mass-Gathering-Medicine, through evaluation of throughput in terms of deliverables/per unit time, against established Standard-Operating-Procedures for various clinical, investigation, drug-dispensing, patient-transfer, administrative and patient-safety algorithms.

The average range of patient encountertime, waiting-time, turnaround-time were assessed throughout various echelons of healthcare under a patient-centric healthcare delivery model. Even low-acuity patients were attended round-the-clock. Subjective assessment of communication-time, visit-time and doctorpatient interaction on-site was done. Encounter-time was defined as time taken by the patient for a healthcare operation such as outpatient attendance, investigation, drug-dispensing, minor-procedures and ambulance transfers. Waiting-time was defined as pre-operation waiting time due to resource limitations attributable to health-system, while excluding waiting-time attributable to patient or otherwise such as delayed reporting, traffic-conditions and post-attendance time for decisions or other personal reasons. Turnaround-time was defined as time taken to complete a task incorporating both operation and waiting-time, as applicable. Communication-time/reportingtime/accessibility-time or patient-rescue time was defined as time taken for health-intelligence to reach the doctor. Visit-time was defined as time taken for visit by medical team to reach the patient through ambulance/foot. Doctor-patient interaction on-site was defined as time taken for elicitation of relevant history and administration of first-aid, if any. The turnaround-time for healthcare personnel was compared between site visits and that with patient being brought to healthcare facility. Health emergency was defined as any condition threatening the life or limb of a patient. Initiation of definitive-care was the end/start point of defining upstream (pre-hospital) and downstream (hospital-care) processes, being prior and after respectively. Dynamic evaluation was carried out to cater for variation and heterogeneity.

\section{Results}

A total of 394013 patients comprising 225 103 males (57.1\%), and 168910 females (42.9\%) were attended by a team of 144 doctors including 50 specialists, 146 paramedics and 74 ancillary staff. The patient distribution in mobile medical task-forces, static-clinics and tent-clinics was 13473,374475 and 5135 patients. Out of 930 secondary-care and 523 tertiary-care referrals, 585 and 495 patients were institutionalized respectively. Total secondary-care bed days were 4626, average bed occupancy being $77.78 \%$ for one month around Hajj and $32 \%$ otherwise. Pooled unadjusted average length of stay of all patients was three days. 1505 minor surgical and 770 orthopaedic procedures were performed. 7850 laboratory, 2074 imaging and 1159 electrocardiograms were carried out.

Massive surge of patients overwhelmed the throughput capacities of outpatient attendance, pharmacy, laboratory, imaging, ambulance, referrals and documentation. There was delay in attendance, suspicion, diagnosis and isolation of patients with communicable infections. Average encounter-time, waiting-time and operation turnaround-time for patients, 
procedures, investigations and ambulance operations is depicted in Table 1. The turnaround-time for healthcare personnel has been compared in Table 2.

\section{Discussion}

Golden-hour

Golden-hour conceptualizes early arrival of patient to definitive-care enabling early recog-

Table 1. Indian Medical Mission for Hajj-2016: encounter, waiting and operation turnaround time for patients, procedures, investigations and ambulance operations

\begin{tabular}{|c|c|c|c|c|}
\hline No. & Patient-care variables & $\begin{array}{l}\text { Encounter } \\
\text { time } \\
\text { (minutes) }\end{array}$ & $\begin{array}{l}\text { Waiting time } \\
\text { (minutes) }\end{array}$ & $\begin{array}{c}\text { Operation } \\
\text { turnaround } \\
\text { time } \\
\text { (minutes) }\end{array}$ \\
\hline \multicolumn{5}{|c|}{$\begin{array}{l}\text { Pre-Hospital patient care (on-site primary-care through mobile-medical-task-force } \\
\text { during mass-gathering congregations) }\end{array}$} \\
\hline 1 & $\begin{array}{l}\text { Rescue/reporting/accessibility time to healthcare } \\
\text { professional }\end{array}$ & $1-30$ & $0-5$ & $20-60$ \\
\hline 2 & Immediate first-aid & $5-20$ & $0-5$ & $20-60$ \\
\hline 3 & Ambulance arrival at site of injury/first-aid & $0-15$ & $0-15$ & $30-150$ \\
\hline 4 & $\begin{array}{l}\text { Stretcher/wheelchair transfer from site of first-aid } \\
\text { to ambulance/primary-care/secondary-care }\end{array}$ & $0-20$ & $0-2$ & $30-150$ \\
\hline 5 & $\begin{array}{l}\text { Ambulance transfer from site of first-aid } \\
\text { to primary/secondary-care }\end{array}$ & $10-40$ & $10-20$ & $30-150$ \\
\hline \multicolumn{5}{|c|}{ Pre-Hospital patient care (static-clinic based primary-care) } \\
\hline 1 & Low acuity patients & $2-10$ & $0-60$ & $2-60$ \\
\hline 2 & High acuity patients & $20-40$ & $0-5$ & $10-60$ \\
\hline 3 & Checking of vitals & $3-5$ & $0-30$ & $3-30$ \\
\hline 4 & Systemic examination & $2-15$ & $0-15$ & $2-15$ \\
\hline 5 & Blood glucose by glucometer & $2-3$ & $0-40$ & $2-40$ \\
\hline 6 & Collection of medicines from pharmacy & $2-10$ & $0-60$ & $2-60$ \\
\hline 7 & $\begin{array}{l}\text { Ambulance transfer from static-clinic } \\
\text { to secondary/tertiary-care }\end{array}$ & $30-90$ & $0-60$ & $30-150$ \\
\hline \multicolumn{5}{|c|}{ Pre-Hospital patient care (tent-clinic based primary-care during five critical days of Hajj) } \\
\hline 1 & Low acuity patients & $2-10$ & $0-20$ & $2-20$ \\
\hline 2 & High acuity patients & $20-40$ & $0-2$ & $20-40$ \\
\hline 3 & Checking of vitals & $3-5$ & $0-10$ & $3-10$ \\
\hline 4 & Systemic examination & $2-15$ & $0-10$ & $2-25$ \\
\hline 5 & Blood glucose by glucometer & $2-3$ & $0-10$ & $2-10$ \\
\hline 6 & Collection of medicines from pharmacy & $2-10$ & $0-20$ & $2-20$ \\
\hline 7 & $\begin{array}{l}\text { Ambulance transfer from tent-clinic } \\
\text { to secondary/tertiary-care }\end{array}$ & $10-20$ & $0-30$ & $10-60$ \\
\hline \multicolumn{5}{|c|}{ Hospital-based patient care (secondary-care) } \\
\hline 1 & Low acuity patients & $2-5$ & $0-60$ & $2-60$ \\
\hline 2 & High acuity patients & $20-40$ & $0-2$ & $20-40$ \\
\hline 3 & Electrocardiogram & 5 & $0-30$ & $5-30$ \\
\hline 4 & Urine routine and microscopy & 10 & $0-20$ & $10-20$ \\
\hline 5 & Blood glucose by glucometer & $2-3$ & $0-40$ & $2-40$ \\
\hline 6 & Malaria/ Dengue/HCV by rapid kits & 30 & $0-30$ & $30-60$ \\
\hline 7 & Haematology tests & 30 & $0-30$ & $30-60$ \\
\hline 8 & Clinical chemistry tests & 30 & $0-30$ & $30-60$ \\
\hline 9 & Manual X-ray & 20 & $0-30$ & $30-60$ \\
\hline 10 & Ultrasonography & 5 & $0-20$ & $5-20$ \\
\hline 11 & Minor surgical procedures & 30 & $0-60$ & $30-60$ \\
\hline 12 & Orthopaedic procedures & 30 & $0-60$ & $30-60$ \\
\hline 13 & Collection of medicines from pharmacy & $2-10$ & $0-60$ & $2-60$ \\
\hline 14 & $\begin{array}{l}\text { Ambulance transfer from secondary-care } \\
\text { to tertiary-care }\end{array}$ & $30-60$ & $0-60$ & $60-180$ \\
\hline
\end{tabular}


Table 2. Comparative analysis of average time of initiation of definitive-care

\begin{tabular}{|c|l|c|c|}
\hline No. & \multicolumn{1}{|c|}{ Healthcare personnel turnaround time } & $\begin{array}{c}\text { Site/home } \\
\text { visit by doc- } \\
\text { tor }\end{array}$ & $\begin{array}{c}\text { Patient } \\
\text { brought to } \\
\text { healthcare } \\
\text { facility }\end{array}$ \\
\hline 1 & Mobile-medical-task-force during Mass-gathering congregations & $20-60$ & $5-30$ \\
\hline 2 & Tent-clinic based primary-care & $10-30$ & $5-15$ \\
\hline 3 & Static-clinic based primary-care & $10-60$ & $5-15$ \\
\hline 4 & Hospital-based secondary-care & $10-60$ & $5-30$ \\
\hline 5 & Tertiary-care & & \\
\hline
\end{tabular}

nition of disease-condition, triage, initiation of resuscitation, control of bleeding, intravenous fluids, antimicrobials, analgesics, investigations and treatment/surgery, thereby positioning the patient on the path to recovery [5]. The model has evolved with expansion in scope from trauma to head-injury, sepsis, shock, stroke, neonates, antimicrobial therapy, pressure-ulcer; weaning of mechanical resuscitation, ICU admissions, ischemia, heat-stroke, laboratory, imaging, referral and evacuation etc. as well as expansion in time to evolve the "platinum halfhour", "golden 10 minutes" and "silver-day" [6-9].

Golden-hour is an essential pragmatic tool in pre-hospital care in both clinical and logistic fronts. Golden-hour subsumes time to reach definitive-care, thereby including communication/accessibility/reporting time, doctor-patient interaction time and stabilization-time allowing critical clinical interventions. Significant associations with deterioration of patient's condition have been found with each incremental minute of patient arrival to definitive-care [6-9]. It is important to note that doctor-patient interaction time and stabilization-time may be as long as 27.55 minutes, which may nudge into the golden-hour [10]. Logistics of communication, evacuation, terrain and weather considerations are deterministic in outcome [11-15].

There are three axes to golden-hour. Firstly, golden-hour in a patient-centric scenario incorporates resource maximization towards protocolized treatment. Secondly, golden-hour in an incident-accident centric scenario involves triage and evacuation under the 'best for most' approach. Thirdly, golden-hour in mass-gathering-medicine insinuates a resource-limited scenario with surge of both high-acuity and low-acuity patient-crowds from diverse sociocultural backgrounds, expectations and needs [16]. The plot of golden-hour in mass-gatheringmedicine is shown in Fig. 1.

While patients' arrival within first 60 minutes has been associated with better prognosis and early discharge, increased out-of-hospital time is associated with the contrary. Pre-hospital life-saving procedures such as intubation may not reduce morbidity [17-18]. Communication of information is critical for preparedness. Even when encounter-time and waiting-time may be few minutes, together they lead to a turnaround-time spilling out of the goldenhour. Ambulance turnaround-time are affected by confusing addresses of camps/sites, distance, overwhelming vehicle and pedestrian traffic as well as reorganized routes, which may lead to unusual delay. Huge surge of patients lead to crowding of healthcare facilities reduces access to more deserving patients. Little understanding of health emergencies by patients lead to increased waiting-time for patients deserving early attention $[6,19]$.

\section{Throughput in healthcare}

Human system is an extremely complex system where existing knowledge is complemented by deductive algorithm and modelling to design protocolized goal-directed diagnosis and treatment modules. The throughput involving human lives is dependent on doctor-patient interactions, which incorporates real-life human dependence at both ends; and poses limitations in simulation-based real-time preparedness. Despite advances in biomedical engineering, the throughput in health-systems



Fig. 1. Illustration of Golden-Hour in Mass-Gathering Medicine. 
is not comparable with inanimate entities such as data packets, industrial processes and products; which function in systems invented, designed, standardized and calibrated through calculations and simulations. The throughput in medicine and health systems has had no defined maximum since antiquity, even in the absence of stochastic and deterministic deductions and quantifiable indicators. Disasters, wars and pandemics have exemplified the doctor-patient equation in situations of overwhelming throughput. The concept of maximum theoretical throughput may at best be applied to quality healthcare including documentation which is restricted in scope in an overwhelming throughput scenario. The maximum achievable throughput is defined by resource-limitations $[20,21]$.

Golden-hour in mass-gathering medicine

Golden-hour paradigm in mass-gathering medicine entwines along healthcare availability, accessibility, efficiency and interoperability; expanding from the patient-centric to publichealth centric approach. Operational stringencies exist parallel to infrastructural and provisioning stringencies in makeshift healthcare facilities with intricate operational, procurement, distribution and disposal logistics. Overwhelming number of patients may lead to downgrading of medical centres to resourcelimited setups, compromising standards of healthcare, clientele satisfaction and resource security. ${ }^{22}$ It also leads to physical, mental and compassion fatigue amongst healthcare-personnel. Healthcare availability involves dynamic planning of human, auxiliary and ancillary resources such as infrastructure, medicines, equipment and consumables. Human resources are a critical component of goldenhour mandating deployment discretion. Healthcare professionals are often required to multitask in resource-limited settings which hamper the technical efficiency towards focused and dedicated clinical work. Accessibility can be improved by resource planning, information technology, communications, surveillance systems and outreach activities. Internal communication for healthcare professionals should include information on local diseases, transmission, antimicrobial resistance, availability of medicines through acquired health intelligence $[20,21]$.

Population-based approach to Golden-hour

The role of population is often not discussed within the Golden-hour concept. Golden-hour pre-hospital care is ought to be provided by people such as family, friends and the first people noticing the need; much before the arrival of first responders, paramedics or doctors. While significant expertise in first-aid may exist in progressive Western communities, negligible help is available to victims in most developing communities leading to increased morbidity and mortality. The problem of spectator-inertia around accidents mandates behavioural change in attitude of the masses towards philanthropic efforts. Community level expertise development programs can enable rapid firstaid availability. Calling for a paramedic/doctor to reach the site is time consuming and doesn't lead to definitive-treatment as most cases need to be shifted to hospitals for simple measures such as fluid resuscitation, application of plaster-casts or administration of analgesics, antiallergics etc. Instead of sending a representative from the community to call for medical help, the time and effort should be utilized towards providing initial care and transportation support to the victim towards the hospital for definitive-care. Patient being brought to definitive-care reduces treatment initiation-time by $50 \%$ as seen in this study. While the patient is brought early to a resourcerich environment compared to pre-hospital care, it also furthers simultaneous domiciliary care and monitoring of multiple patients. A multifold availability of doctor and auxiliary health professionals at medical facility facilitates adherence to protocols and optimization of processes, thereby improving outcome and streamlining throughput $[19,23,24]$.

The situational-analysis of operations throughput highlights wastage of considerable time due to mobilization of medical team from the hospital to reach the patient on-site due to calls for low/moderate-acuity complaints resulting from inability of the patients to judge medical emergencies. It has been proven that trauma team activation doesn't guarantee better survival [19]. Visits consume the turnaround time for healthcare professionals, thereby reducing their availability to attend to deserving patients in need, and diverted critical healthcare resources away from emergency situations. Sometimes, visit come at the cost of leaving the medical facility without a doctor. In any resource limited scenario, most patients who deserve time, access definitive-care beyond the golden-hour [7, 8, 25, 26].

There is an evolving paradigm of healthcare which is as explicit as right-to-heath or implicit under human/social rights/security within the 
boundaries defined by a nation/state for its citizens, or by an employer/insurer for beneficiaries. The kingdom of Saudi Arabia has been magnanimous to extend comprehensive quality healthcare to Hajj pilgrims from all over the world, through a robust and efficient statesponsored single-tier health system, a vanguard equity healthcare-model difficult to emulate. Nevertheless, operations throughput gets overwhelmed during Hajj at all healthcare facilities $[1,2,25]$.

The golden-hour is not a blind concept around buying time; rather it is a dynamic concept requiring reasonable discretion and prudence; failing which there exist limitations to its applicability. Overwhelming fluid resuscitation and extensive procedures may lead to procedural errors, transmission of infections and antimicrobial overuse [17, 27-30]. Since the study catered to 4.5 lakh patients across a wide network of medical facilities in a setting of mass-gathering medicine, limitations exist due to variability in patients, sites and medical facilities. Elements of bias and confounding at patient and doctors' may not be fully account- ed. The variability of operations as well as that of observers may limit the exhaustive collation of data.

\section{Conclusions}

Time being a crucial factor in the complexity of medical-care, operations throughput remains an important determinant towards availability, accessibility, efficiency and interoperability of bottlenecks, thereby being a determinant of golden-hour in mass-gatheringmedicine. Early transportation of patient to definitive-care reduces treatment initiationtime by $50 \%$ thereby improving outcome, and consequentially emphasizing patient-evacuations personal visits and interventions by medical/trauma team. Evidence-based guidelines, standards, alert and response systems need to be developed with international cooperation and networking for enhancing capability and core competency. Golden-hour needs to be emphasized under a population-based approach targeting the clientele towards administering first-aid and reaching out to hospital within the golden-hour.

\section{References}

1. Kollek D. An intro to mass gatherings. Centre for Excellence in Emergency Preparedness. Ontario. Canada. 2014:1-15. www.ceep.ca/publications/ Mass_Gatherings.pdf. Accessed 2014.

2. WHO. Epidemic and Pandemic Alert and Response. Communicable Disease alert and response for mass gatherings. WHO/HSE/EPR/2008/8 Technical Workshop. Geneva-Switzerland, 29-30 Apr 2008:1-29. http://www.who.int/csr/mass_gathering/ en/. Accessed 2015.

3. Memish ZA, Stephens GM, Steffen R, Ahmed QA. Emergence of medicine for mass gatherings: lessons from the Hajj. Lancet Infect Dis. 2012;12(1):5665. http://www.ncbi.nlm.nih.gov/pubmed/22192130. Accessed 2012.

4. Shujaa A, Alhamid S. Health response to Hajj mass gathering from emergency perspective, narrative review. TurkJ Emerg Med. 2015;15(4):172-176. http://www.ncbi.nlm.nih.gov/pmc/articles/ PMC4882208. Accessed 2015.

5. Muck F, Wirth K, Muggenthaler $M$, et al. Pretreatment mass casualty incident workflow analysis : Comparison of two level 1 trauma centers. Unfallchirurg. 2016;119(8):632-41. http://www.ncbi. nlm.nih.gov/pubmed/27351989. Accessed 2016.

6. Dinh MM, Bein K, Roncal S. Redefining the golden hour for severe head injury in an urban setting: the effect of prehospital arrival times on patient outcomes. Injury. 2013 May;44(5):606-10. doi: 10.1016/j.injury.2012.01.011.

7. Van Zanten AR. The golden hour of antibiotic administration in severe sepsis: avoid a false start striving for gold. Crit Care Med. 2014;42(8):19311932. doi:10.1097/CCM.0000000000000363.

8. Heled Y, Rav-Acha M, Shani Y, Epstein Y, Moran DS. The "golden hour" for heatstroke treatment. Mil Med. 2004;169(3):184-186. http://www.ncbi.nlm.nih. gov/pubmed/15080235. Accessed 2004.

9. Wyen $H$, Lefering $R$, Maegele $M$, et al. The golden hour of shock - how time is running out: prehospital time intervals in Germany a multivariate analysis of 15103 patients from the Trauma Register DGU(R). Emerg Med J. 2013;30(12):1048-1055. doi:10.1136/emermed-2012-201962.

10. Vanderschuren M, McKune D. Emergency care facility access in rural areas within the golden hour?: Western Cape case study. Int J Health Geogr. 2015;14:5. doi:10.1186/1476-072X-14-5.

11. Meskere Y, Dinberu MT, Azazh A. Patterns And Determinants Of Pre-Hospital Care Among Trauma Patients Treated In Tikur Anbessa Specialized Hospital, Emergency Department. Ethiop Med J. 2015;53(3):141-149. http://www.ncbi.nlm.nih.gov/ pubmed/26677524. Accessed 2015.

12. Khan ID, Basu A, Trivedi S, Prasad M, Rappai TJ, Narayanan RV, Ramphal SK, Singh NS. Battlefield, 
Bullets and Bugs: The vicious Circle in Gunshots. J Basic \& Clin Med. 2016;5(1):11-12. www.sspublications.org/index.php/JBCM/article/view/65. Accessed 2016.

13. Khan ID. Extreme Altitude Pulmonary Oedema in Acclimatized Soldiers. MJAFI. 2012;68(4):339345. (PMID - 24532901)

14. Khan ID. Comorbid Cerebral and Pulmonary Edema at $7010 \mathrm{M} / 23000 \mathrm{Ft}$ : An Extreme Altitude Perspective. J Medicine. 2013;14(2):153-155.

15. Khan ID. Cerebral Venous Sinus Thrombosis (CVST) Masquerading as High Altitude Cerebral Edema (HACE) at Extreme Altitude $(6700 \mathrm{~m} / 22000$ ft). Int J Travel Med Glob Health. 2016;4(3):65-67.

16. Kotwal RS, Howard JT, Orman JA, et al. The Effect of a Golden Hour Policy on the Morbidity and Mortality of Combat Casualties. JAMA Surg. 2016;151(1):15-24. doi:10.1001/jamasurg.2015.3104.

17. Lerner EB, Moscati RM. The golden hour: scientific fact or medical "urban legend"? Acad Emerg Med. 200l;8(7):758-60. http://www.ncbi.nlm. nih.gov/pubmed/11435197. Accessed 2001.

18. Platts-Mills TF, Evans CS, Brice JH. Prehospital Triage of Injured Older Adults: Thinking Slow Inside the Golden Hour.J Am Geriatr Soc. 2016. http://www. ncbi.nlm.nih.gov/pubmed/27556573. Accessed 24 Aug 2015.

19. Samplais JS, Lavoie A, Williams JI, et al. Impact of on-site care, prehospital time, and level of inhospital care on survival in severely injured patients. J Trauma. 1993;34:252-261. http://www.ncbi.nlm.nih. gov/pubmed/8459466. Accessed 1993.

20. Khan ID, Gupta N, Rangan NM, Singh R, Sharma AK, Khurana A, Rudra P, Krushnarao MS. Evaluation Of Pre and Post Analytical Variables in Clinical Microbiology Services in Multidisciplinary ICU of a Medical College And Tertiary Care Hospital. J Basic \& Clin Med. 2016;5(1):2-4. www.sspublications. org/index.php/JBCM/article/view/63. Accessed 2016.

21. Khan ID, Sahni AK. Rapid Diagnosis of Dengue Outbreaks in Resource Limited Facilities. West Indian Medical Journal. 2016. E-pub ahead of print. 10:7727/wimj.2016.095.

22. Ahmed QA, Barbeschi M, Memish ZA. The quest for public health security at Hajj: the WHO guidelines on communicable disease alert and response during mass gatherings. Travel Med Infect Dis. 2009 ;7(4):226-30. http://www.ncbi.nlm.nih.gov/ pubmed/1917105. Accessed 2009.

23. Newgard CD, Schmicker RH, Hedges JR, et al. Emergency Medical Services Intervals and Survival in Trauma: Assessment of the "Golden Hour" in a North American Prospective Cohort. Ann Emerg Med. 2010;55(3):235-246.4. doi: 10.1016/j.annemergmed. 2009.07.024.

24. Turkestani A, Balahmar M, Ibrahem A, Moqbel E, Memish ZA. Using health educators to improve knowledge of healthy behaviour among Hajj 1432 (2011) pilgrims. East Mediterr Health J. 2013;19(2):912. http://www.ncbi.nlm.nih.gov/pubmed/24673092. Accessed 2013.

25. Mandourah Y, Ocheltree A, Al Radi A, Fowler R. The epidemiology of Hajj-related critical illness: lessons for deployment of temporary critical care services. Crit Care Med. 2012;40(3):829-34. http:// www.ncbi.nlm.nih.gov/pubmed/22080635. Accessed 2012.

26. Memish ZA, Assiri A, Turkestani A, Yezli S, Al Masri M, Charrel R, et al. Mass gathering and globalization of respiratory pathogens during the 2013 Hajj. Clin Microbiol Infect. 2015;21(6):571.1-8. http:// www.ncbi.nlm.nih.gov/pubmed/25700892. Accessed 2015.

27. Taghavi S, Vora HP, Jayarajan SN. Prehospital intubation does not decrease complications in the penetrating trauma patient. Am Surg. 2014. 80(1):914. http://www.ncbi.nlm.nih.gov/pubmed/24401498. Accessed 2014.

28. Jacob M, Kumar P. The challenge in management of hemorrhagic shock in trauma. Med J Armed Forces India. 2014 Apr;70(2):163-9. http://www.ncbi. nlm.nih.gov/pmc/articles/PMC4017195

29. Jindal AK, Pandya K, Khan ID. Antimicrobial Resistance: A public health challenge. Med J Armed Forces. India. 2014;71(2):178-181. http://www.ncbi. nlm.nih.gov/pubmed/25859082. Accessed 2014.

30. Khan ID, Sahni AK, Bharadwaj R, Lall M, Jindal AK, Sashindran VK. Emerging Organisms in a Tertiary Healthcare Set Up. Med J Armed Forces. India. 2014;70(2):120-128. http://www.ncbi.nlm.nih.gov/ pubmed/24843199. Accessed 2014. 